\title{
EXPERIMENTAL STUDY ON THE LOADING AND SCOUR OF THE JACKET TYPE OFFSHORE WIND TURBINE FOUNDATION
}

\author{
Ray-Yeng Yang ${ }^{1}$, Hsin-Hung Chen ${ }^{1}$, Hwung-Hweng Hwung ${ }^{1}$, Wen-Pin Jiang ${ }^{1}$ and Nian-Tzu \\ $\mathrm{Wu}^{2}$
}

\begin{abstract}
A 1:36 scale model tests were carried out in the Medium Wave Flume (MWF) and Near-shore Wave Basin (NSWB) at the Tainan Hydraulics Laboratory (THL) with the jacket type offshore wind turbine foundation located in the test area. The loading of typhoon wave with current on the jacket type offshore wind turbine foundation was investigated in the MWF with fixed bed experiment. Meanwhile, the scour around the jacket type offshore wind turbine foundation exposed to wave and current was conducted in the NSWB with the moveable bed experiment. Two locations (water depth $12 \mathrm{~m}$ and $16 \mathrm{~m}$ ) of the foundations are separately simulated in this study. Based on the analysis from the former NSWB experimental results, the suitable scour protection of a four-layer work around the foundation is also proposed to the impact of scour. Finally, a four-layer scour protection is tested and found to be effective in preventing scour around jacket type foundation of offshore wind turbines at water depth $12 \mathrm{~m}$ and $16 \mathrm{~m}$.
\end{abstract}

Keywords: loading; scour; offshore wind turbine; jacket type foundation; fixed bed experiment; mobile bed experiment; scour protection

\section{INTRODUCTION}

The growing concern in the 1990s over $\mathrm{CO}_{2}$-forced global warming has given new life to the prospects for greater use of wind turbines because of their credentials as non-polluting generators powered by winds created by solar energy, a renewable resource. Therefore over the past two decades, on-shore wind energy technology has seen a ten-fold reduction in cost and is now competitive with fossil and nuclear fuels for electric power generation in many areas of the world. As a direct consequence of the Kyoto Protocol there is a new impetus in developing the capacity of offshore wind farms to provide a significant percentage of the target renewable energy quota. Offshore wind energy began in shallow waters of the North Sea where the abundance of sites and higher wind resources are more favorable by comparison with Europe's land-based alternatives. All today's offshore wind farms producing energy (start 2007) are located in shallow waters; they are either founded on monopoles or on gravity based caissons. However transitional substructure of the offshore wind turbines will be replaced by fixed bottom systems that use a wider base with multiple anchor points like those frequently used in oil and gas industry. In order to investigate the loading on the jacket type offshore wind turbine foundation, the effect of typhoon wave together with current was conducted in the Medium Wave Flume (MWF, $200 \mathrm{~m} \times 2 \mathrm{~m} \times 2 \mathrm{~m}$ ) by 1:36 scale in this study. Meanwhile, the stability of the seabed around the wind turbine foundations is another one of the major challenges in offshore wind farm design. The design of the offshore turbines has to include an assessment of the possible long-term morphological development occurring in the design period, and an assessment of the local erosion caused by the presence of the foundations themselves.

Within the TAIWAN a range of seabed locations from Chang-Hwa to Yun-Lin, mid western coast of Taiwan, have been licensed for development of offshore wind farms. One of the key factors in the sitting and construction of offshore wind farms is the influence of the seabed geology and sedimentary environment on the foundation design and stability over the lifetime of the structure. Therefore, the objective of this study is to improve understanding of scour behavior and to aid the design of scour protection systems for offshore jacket type foundations located on sandy seabed. A physical model test study has been performed on the occurrence and prevention of erosion holes (scour) around jacket type foundations of offshore wind turbine on sandy soils. The scour around the jacket type offshore wind turbine foundation exposed to wave and current is conducted in the Near-Shore Wave Basin (NSWB, $150 \mathrm{~m} \times 60 \mathrm{~m} \times 1.5 \mathrm{~m}$ ) of Tainan Hydraulics Laboratory (THL) with the 1:36 scale mobile bed experiment. Two locations (water depth $12 \mathrm{~m}$ and $16 \mathrm{~m}$ ) of the foundation are separately simulated in this study. The maximum scour depth and the potential impact scour area around the jacket type offshore wind turbine foundation is analyzed from the result of the mobile bed experiment. In order to prevent the erosion, the suitable scour protection with rock dump layer is also proposed to reduce the impact of scour.

\section{HYDRODYDYNAMIC AND MORPHOLOGIC BACKGROUND}

Offshore wind turbines are presently perceived as one of the most environmentally friendly sources of electrical power, being a non-polluting renewable resource that causes minimal human, ecological and environmental impacts. Offshore wind farms are now being proposed for, or built in, increasingly hostile hydrodynamic environments. Many candidate sites for offshore wind turbine parks are located on seabed of

\footnotetext{
${ }^{1}$ Tainan Hydraulics Laboratory, National Cheng Kung University, $5^{\text {th }}$., No. 500, Sec. 3, Anming Rd., Tainan, 709, TAIWAN

${ }^{2}$ SINOTECH ENGINEERING CONSULTANTS, LTD, 171, Nanking E. Rd. Sec. 5, Taipei, 10570, TAIWAN
} 
mobile sediments in Taiwan mid-western coast area (Chang-Hwa and Yun-Lin area) for the near future. Thirty sets of 3.6MW (or 5MW) jacket type offshore wind turbines will be established under the plan of the Taiwan Power Company (TPC) before 2015. The range of water depth for this offshore wind turbine park is located from $10 \mathrm{~m}$ to $20 \mathrm{~m}$ with mild slope bottom(s=1/150 1/600). The sediment in-situ is fine sand of a median diameter of $\mathrm{d} 50=0.2 \mathrm{~mm}$. Two locations (water depth $12 \mathrm{~m}$ and $16 \mathrm{~m}$ ) of the wind turbine foundation (shown in Fig.1) are separately simulated in this study. Although the design life of the wind park is 20 years, however due to the consideration of extreme wave loading, the model have to be performed for 1:100 year return period typhoon wave for short-term impact and critical monsoon wave for long-term loading. The maximum local current of this area is $1.0 \mathrm{~m} / \mathrm{s}$, this is a depth averaged current for both tidal and wind driven current. The angle between the incident wave and current is $90^{\circ}$. Due to high tidal range of the studied area, different water level is also considered for every test. All the test conditions of the fixed-bed experiment and the mobile bed experiment are shown in Table 1 and Table2.
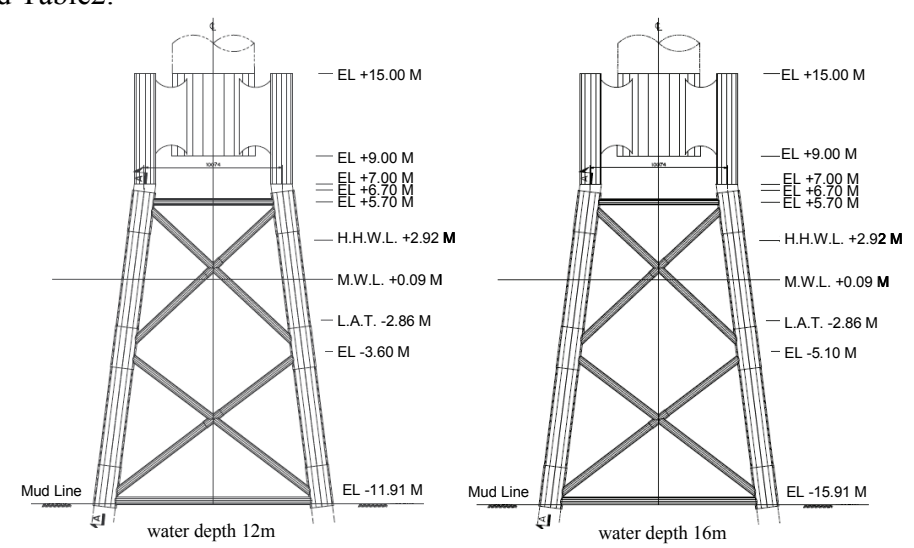

Figure 1. Two locations (water depth $12 \mathrm{~m}$ and $16 \mathrm{~m}$ ) of the jacket type wind turbine foundation.

\begin{tabular}{|c|c|c|c|c|c|}
\hline Water depth (m) & tidel level (m) & water level (m) & wave height $(\mathrm{m})$ & wave period (sec) & tidal current $(\mathrm{m} / \mathrm{s})$ \\
\hline \multirow{3}{*}{12} & D.W.L. & 4.22 & \multirow{3}{*}{6.77} & \multirow{3}{*}{11.74} & \multirow{3}{*}{0.0} \\
\hline & H.H.W.L. & 2.92 & & & \\
\hline & M.W.L. & 0.09 & & & \\
\hline \multirow{3}{*}{16} & D.W.L. & 4.22 & \multirow{3}{*}{7.72} & \multirow{3}{*}{11.67} & \multirow{3}{*}{1.0} \\
\hline & H.H.W.L. & 2.92 & & & \\
\hline & M.W.L. & 0.09 & & & \\
\hline
\end{tabular}

\begin{tabular}{|c|c|c|c|c|c|c|}
\hline test case & $\begin{array}{l}\text { water } \\
\text { depth } \\
\text { (m) }\end{array}$ & $\begin{array}{l}\begin{array}{l}\text { wave } \\
\text { height } \\
(\mathrm{m})\end{array} \\
\end{array}$ & $\begin{array}{l}\text { wave } \\
\text { period } \\
(\mathrm{sec})\end{array}$ & $\begin{array}{l}\text { water level } \\
(\mathrm{m})\end{array}$ & $\begin{array}{l}\text { tidal } \\
\text { current } \\
\text { (m/s) }\end{array}$ & $\begin{array}{l}\text { Wave } \\
\text { spectrum }\end{array}$ \\
\hline 12TLL(C)M & \multirow{5}{*}{12.0} & \multirow{2}{*}{6.77} & \multirow{2}{*}{11.74} & L.L.W.L.+ Storm surge (-1.56) & \multirow{3}{*}{0.0} & \multirow{10}{*}{ Jonswap } \\
\hline 12TM(C)M & & & & M.W.L.+Storm surge (+1.39) & & \\
\hline 12SLL(C)M & & \multirow{3}{*}{2.5} & \multirow{3}{*}{7.0} & L.L.W.L. $(-2.86)$ & & \\
\hline 12SL(C)M & & & & L.W.O.S.T. $(-2.13)$ & \multirow[t]{2}{*}{1.0} & \\
\hline $12 \mathrm{SM}(\mathrm{C}) \mathrm{M}$ & & & & M.W.L. $(+0.09)$ & & \\
\hline 16TLL(C)M & \multirow{5}{*}{16.0} & \multirow{2}{*}{7.72} & \multirow{2}{*}{11.67} & L.L.W.L.+ Storm surge (-1.56) & \multirow[t]{3}{*}{0.0} & \\
\hline 16TM(C)M & & & & M.W.L.+Storm surge (+1.39) & & \\
\hline 16SLL(C)M & & \multirow{3}{*}{2.5} & \multirow{3}{*}{7.0} & L.L.W.L. $(-2.86)$ & & \\
\hline 16SL(C)M & & & & L.W.O.S.T. (-2.13) & \multirow[t]{2}{*}{1.0} & \\
\hline $16 \mathrm{SM}(\mathrm{C}) \mathrm{M}$ & & & & M.W.L. $(+0.09)$ & & \\
\hline
\end{tabular}

※water level deviation for 100 year return cycle storm surge is $1.3 \mathrm{~m}$

$※ 12$ : $12 \mathrm{~m}$ water depth; $\mathrm{T}$ : typhoon wave; $\mathrm{S}$ : monsoon wave

LL : Lower Low Water Level (L.L.W.L.)

$M(1 s t)$ : Mean Water Level (M.W.L.)

L : Low Water of Ordinary Spring Tide (L.W.O.S.T.)

$C$ : current; $M($ last $)$ : mobile bed 


\section{LOADING ON THE JACKET TYPE FOUNDATION}

Two test items are investigated in the fixed bed experiment, including the total horizontal hydrodynamic force on wind turbine and wave pressure loading distribution along the leg of foundation. Sketch of the fixed-bed experimental setup and process of model construction are shown in Fig.2 and Fig.3.The scale ratio is 1:36 and the Froude law is obeyed in the fixed bed experiment. Experimental analysis of the force measurements is focused on the evaluation of the hydrodynamic force and on the prediction of the maximum breaking wave load on the jacket type offshore wind turbine foundation under shallow water condition. The measurement system of the fixed bed experiment includes wave gages, ADV current meters, pressure gages and the loading table (to see Fig.2). From the fixed bed experimental result, it shows that the vertical wave pressure $\mathrm{P}_{1 / 3}$ and $\mathrm{P}_{1 / 10}$, measured on the pile base under typhoon waves within depth of $12 \mathrm{~m}$ and $16 \mathrm{~m}$ have a highest values on the water surface and with a decreasing trend on going both up and down sides. But the maximum wave pressure $\left(\mathrm{P}_{\max }\right)$ seems to happen on above the water surface rather than near the water surface (to see Fig.4). It is due to the wave breaking on the cylinder that caused the impact pressure going that high. From the result of loading measurement, the maximum forces $\left(\mathrm{F}_{\max }\right)$ under typhoon waves have a higher result while the tide gets higher, which means within the depth of $12 \mathrm{~m}$ and $16 \mathrm{~m}$ the results, will be $1360.1 \mathrm{KN}$ and $1747.2 \mathrm{KN}$. However, if with including current issues the results will increase to $1538.7 \mathrm{KN}$ and $1975.3 \mathrm{KN}$. The results of fixed bed experiment indicate the maximum horizontal forces on the wind turbine foundation have a good agreement with those from the designed values and also validate the wind turbine foundation structure design of the engineering consulting company.

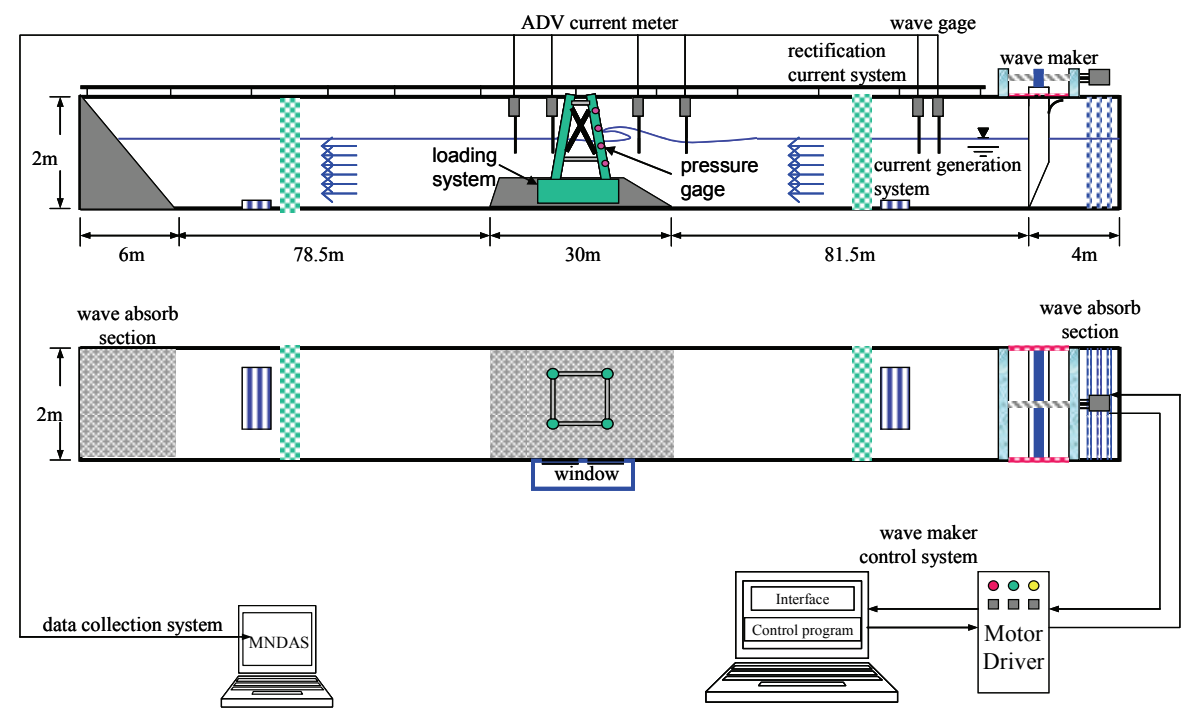

Figure 2. Sketch of the fixed-bed experimental setup.

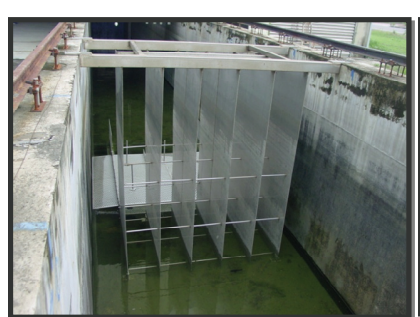

rectification current system

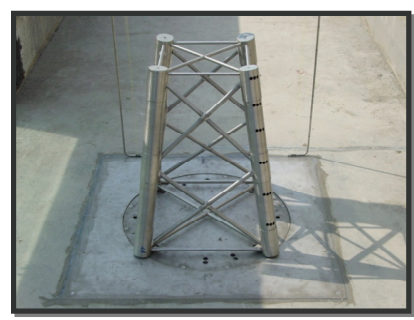

foundation model

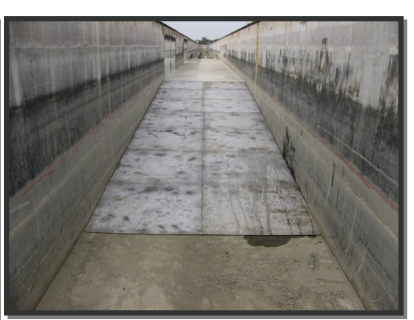

slope of $1 / 10$

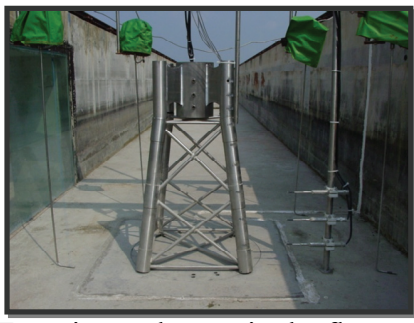

Experimental setup in the flume

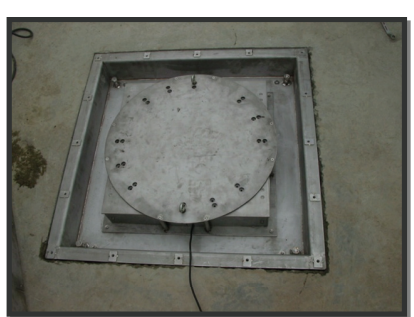

force measurement system

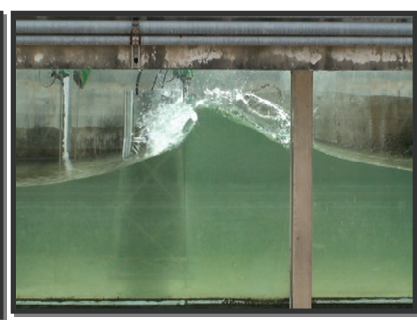

breaking wave impact on the foundation

Figure 3. Process of model construction for the fixed-bed experiment. 


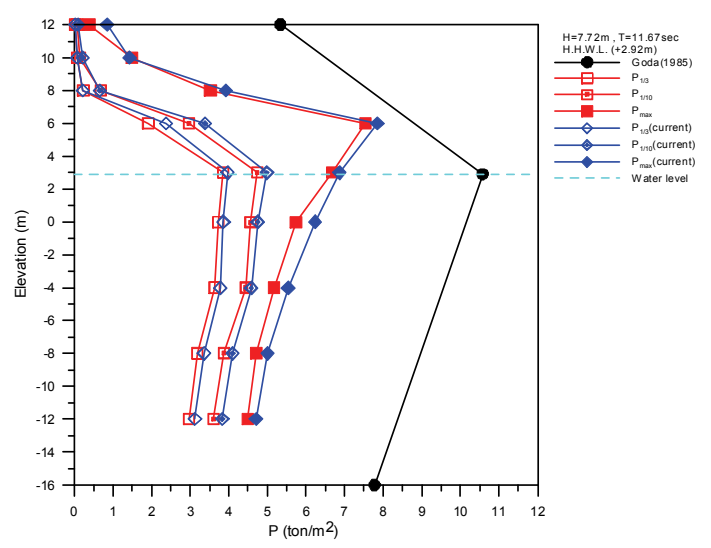

Figure 4. The typhoon wave pressure loading distribution on the offshore (16m water depth) wind turbine foundation at H.H.W.L.

\section{SCOUR AROUND THE JACKET TYPE FOUNDATION WITHOUT PROTECTION}

Two series of physical model tests are performed in this study. The aim of the first test series is to investigate the greatest magnitude of local scour and potential scour area in the sand bed around the jack type foundation with no scour protection. The other series of tests is aimed at the level of protection for proposed scour mitigation under design wave and current conditions and to assess the extent of scouring around the foundations. Layout of $27 \mathrm{mx}$ $19 \mathrm{~m}$ wave-current basin for scour testing is shown in Fig.5. The wave flume passes from right to left and the current-generation flume circulates from downside to upside. The test area with jack type foundation is at the junction of these two flumes. The physical modeling is carried out in this wave-current basin at the Tainan Hydraulics Laboratory (THL) with a scale of 1:36. The sediment used in this experiment is light density (specific gravity, $\gamma=2.02$ ) coal of a median grain size of $d_{50}=0.18 \mathrm{~mm}$ and the model sand bed is $0.35 \mathrm{~m}$ deep, $7.0 \mathrm{~m}$ long and $3.0 \mathrm{~m}$ wide. The equipments and measurement system used in this experiment include irregular wave maker, current-generation system, electrical capacitance wave gauges, ADV current meters and ultrasonic bottom profiler moved by the carriage table $(7 \mathrm{~m} \times 3 \mathrm{~m})$. Before and after the wave-current action for several runs in each test, the bottoms of model sand bed are scanned line by line along the carriage table. Then the topography evolution sea bottom and the scour around jacket type foundation can be analyzed from the measurement data of ultrasonic bottom profiler.

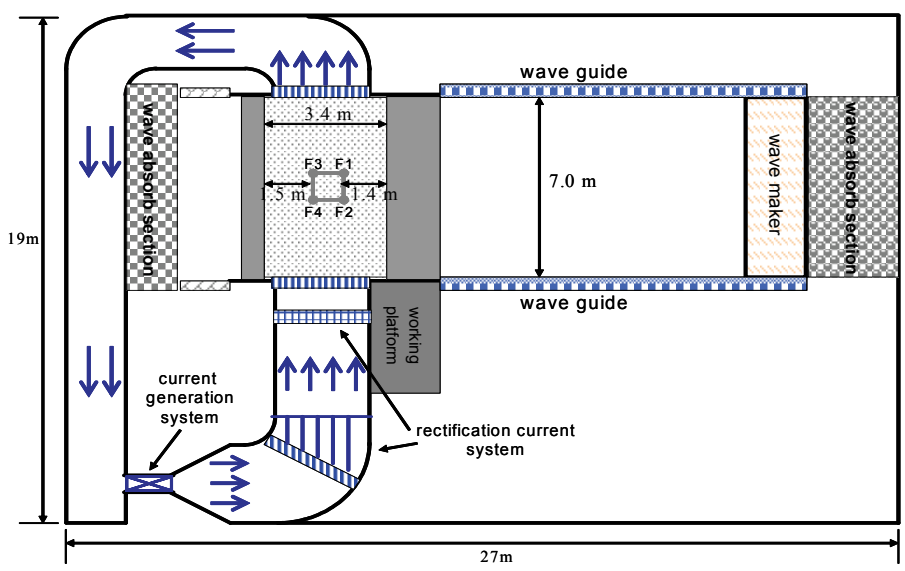

Figure 5. Sketch of the mobile bed experimental setup.

Scour is herein considered to be the lowering of the bed in the vicinity of a marine structure due to local accelerations and decelerations of the near-bed velocities and the associated turbulence (vortices) leading to an increase of the local capacity for sediment transportation. Generally, the near-bed flow around the vertical pile consists of the horseshoe vortex generated at the upstream side of the pile and vortices generated at the lee-side of the pile. Currently with 181 out of 295 foundations for offshore wind turbines, the monopole is the preferred foundation option (Schachner, Josef, 2004). Of these foundations, 169 are driven in sandy soils, which can be more or less susceptible to scour. As a rule of thump, confirmed by experience with other structures, the scour hole can reach a depth of 1.5 times the pile diameter (D). Based on experimental data, Sumer et al. (1992) have 
found for circular pile with its maximum scour depth $d_{s, \max }$ being up to 1.3 times the pile diameter (D). De Bruyn (1988) studied the scour process near a vertical pipe in current and wave conditions. The bed material was natural sand with $d_{50}=0.2 \mathrm{~mm}$. The water depth in the experiment was $0.3 \mathrm{~m}$. The depth-averaged velocity upstream of the pipe was $0.4 \mathrm{~m} / \mathrm{s}$ (mobile bed, $U / U_{c r}>1$ ). The maximum scour depth $\left(d_{s, \max }\right)$ around the pipe was found to be:

$d_{s, \max } / D=\alpha$

With

$\alpha=1.3$ for a current alone,

$\alpha=1.0$ for current and non-breaking waves,

$\alpha=1.9$ for current and breaking waves.

The length of the scour hole was 4D upstream and 6D downstream of the pipe for combined current and wave.

Compared to monopole foundation, jacket type foundation has more complex structure and still no further discuss on its maximum scour depth and the length of the scour hole. Therefore, a physical model test study has been performed on the occurrence and prevention of erosion holes (scour) around jacket type foundation of offshore wind turbine on sandy soils. From Table 3 and Table 4, the experimental results show that the maximum scour depth and the potential impact erosion area around the jacket type foundation located at water depth $12 \mathrm{~m}$ under different hydrodynamic conditions. The diameters (D) of four legs of the foundation are all the same, D equals to $2.08 \mathrm{~m}$ for each leg.

\begin{tabular}{|c|c|c|c|c|c|c|c|c|}
\hline test case & $\begin{array}{l}\text { F1 } \\
(\mathrm{m})\end{array}$ & $\begin{array}{l}\text { F2 } \\
(\mathrm{m})\end{array}$ & $\begin{array}{l}\text { F3 } \\
\text { (m) }\end{array}$ & $\begin{array}{l}\mathrm{F} 4 \\
(\mathrm{~m})\end{array}$ & $\mathrm{F} 1 / \mathrm{D}$ & $\mathrm{F} 2 / \mathrm{D}$ & F3/D & $\mathrm{F} 4 / \mathrm{D}$ \\
\hline 12TLLM & 1.90 & 2.07 & 2.10 & 2.15 & 0.92 & 1.00 & 1.01 & 1.04 \\
\hline 12TMM & 1.26 & 1.15 & 1.39 & 1.29 & 0.61 & 0.55 & 0.67 & 0.62 \\
\hline 12SLLM & 0.68 & 0.58 & 0.59 & 0.79 & 0.33 & 0.28 & 0.28 & 0.38 \\
\hline 12SLM & 0.65 & 0.54 & 0.58 & 0.66 & 0.31 & 0.26 & 0.28 & 0.32 \\
\hline 12SMM & 0.45 & 0.47 & 0.46 & 0.58 & 0.21 & 0.23 & 0.22 & 0.28 \\
\hline 12TЦCM & 2.31 & 2.73 & 2.35 & 2.61 & 1.11 & 1.31 & 1.13 & 1.26 \\
\hline 12TMCM & 2.12 & 2.47 & 2.07 & 2.27 & 1.02 & 1.19 & 1.00 & 1.09 \\
\hline 12SLLCM & 1.23 & 2.23 & 1.25 & 2.18 & 0.59 & 1.07 & 0.60 & 1.05 \\
\hline 12SLCM & 1.15 & 2.18 & 1.16 & 2.22 & 0.55 & 1.05 & 0.56 & 1.07 \\
\hline 12SMCM & 0.88 & 1.88 & 0.92 & 1.93 & 0.42 & 0.90 & 0.44 & 0.93 \\
\hline
\end{tabular}

Table 4. Potential impact erosion area around the jacket type foundation (water depth 12m) under different hydrodynamic conditions.

\begin{tabular}{|c|c|c|c|c|c|c|}
\hline \multirow{2}{*}{ test case } & \multicolumn{6}{|c|}{ Impact area of the different scour depth from foundation leg } \\
\hline & $>0.2 \mathrm{~m}$ & $>0.5 \mathrm{~m}$ & $>1.0 \mathrm{~m}$ & $>1.5 \mathrm{~m}$ & $>2.0 \mathrm{~m}$ & $>2.5 \mathrm{~m}$ \\
\hline 12TLLM & --- & $4 \sim 5 \mathrm{D}$ & $2 \sim 3 D$ & $1 \sim 2 \mathrm{D}$ & $0.5 \mathrm{D}$ & --- \\
\hline 12TMM & --- & $1.5 \sim 2.5 \mathrm{D}$ & $0.5 \sim 1 \mathrm{D}$ & --- & --- & --- \\
\hline 12SLLM & $1 \sim 1.5 \mathrm{D}$ & --- & --- & --- & --- & --- \\
\hline 12SLM & $1 \sim 1.5 \mathrm{D}$ & --- & --- & --- & --- & --- \\
\hline 12SMM & $1 \sim 1.5 \mathrm{D}$ & --- & --- & --- & --- & --- \\
\hline 12TLLCM & --- & $4 \sim 6 D$ & $3 \sim 4 D$ & $2 \sim 2.5 \mathrm{D}$ & $1 \sim 1.5 \mathrm{D}$ & $0.5 \mathrm{D}$ \\
\hline 12TMCM & --- & $3 \sim 4 D$ & $1.5 \sim 3 D$ & $1 \sim 1.5 \mathrm{D}$ & $0.5 \sim 1 \mathrm{D}$ & --- \\
\hline 12SLLCM & --- & $2.5 \sim 4 \mathrm{D}$ & $1 \sim 2 \mathrm{D}$ & $1.5 \mathrm{D}$ & $0.5 \mathrm{D}$ & --- \\
\hline 12SLCM & --- & $3 \sim 4 D$ & $0.5 \sim 2.5 \mathrm{D}$ & $1.5 \mathrm{D}$ & $0.5 \mathrm{D}$ & --- \\
\hline 12SMCM & -- & $1 \sim 2 \mathrm{D}$ & $1 \mathrm{D}$ & $0.5 \mathrm{D}$ & --- & -- \\
\hline
\end{tabular}

For the jacket type foundation located at water depth $12 \mathrm{~m}$, case 12 TLLCM is the most serious scour event exposed to the lowest water level, action combined current and 1:100 year return period typhoon wave. The maximum scour depths around four legs of the jacket type foundation are $F_{1} / D=1.11, F_{2} / D=1.31, F_{3} / D=1.13$ and $F_{4} / D=1.26$ respectively. Fig.6 and Fig.7 show the evolution of maximum scouring depth and the potential impact erosion area around four legs of the jacket type foundation under the case 12TLLCM. In this experiment, the angle between the incident wave and current is $90^{\circ}$. The results show that more serious scour will be induced at legs $F_{2}$ and $F_{4}$ on the up-current side of the foundation. From observations it is estimated the length of the scour holes around 4 legs of the foundation is approximated up to $4 \sim 6$ times the leg diameter. However when foundation 
location changed to $16 \mathrm{~m}$ water depth, the maximum scour depth and the length of the scour hole are less than those obtained from the tests at $12 \mathrm{~m}$ water depth (to see Table 5 and Table 6 ). It is because not only erosion but also re-deposition will occur within the experimental process under the location of $16 \mathrm{~m}$ water depth.
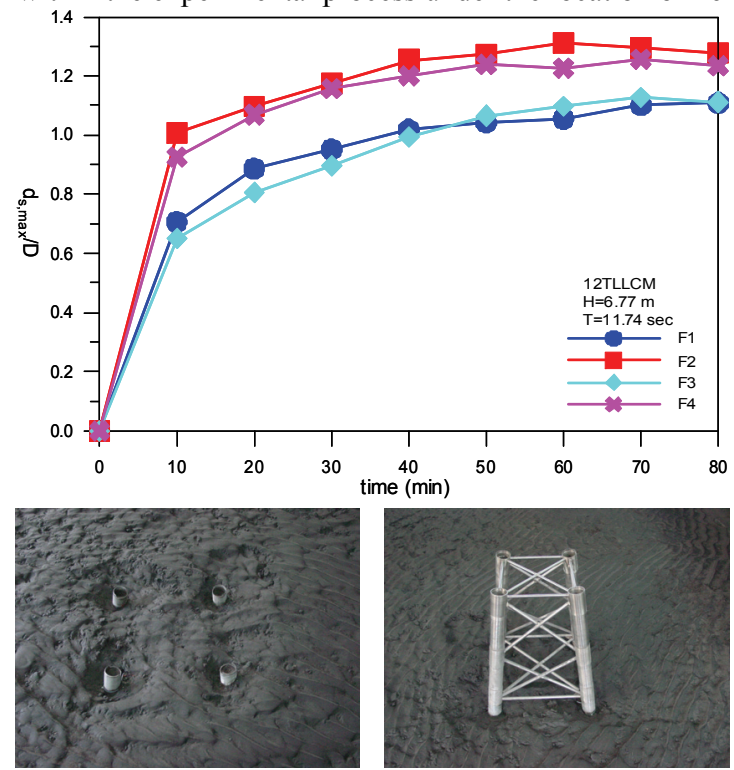

Figure 6. The evolution of maximum scour depth around four legs of the jacket type foundation under the case 12 TLLCM.

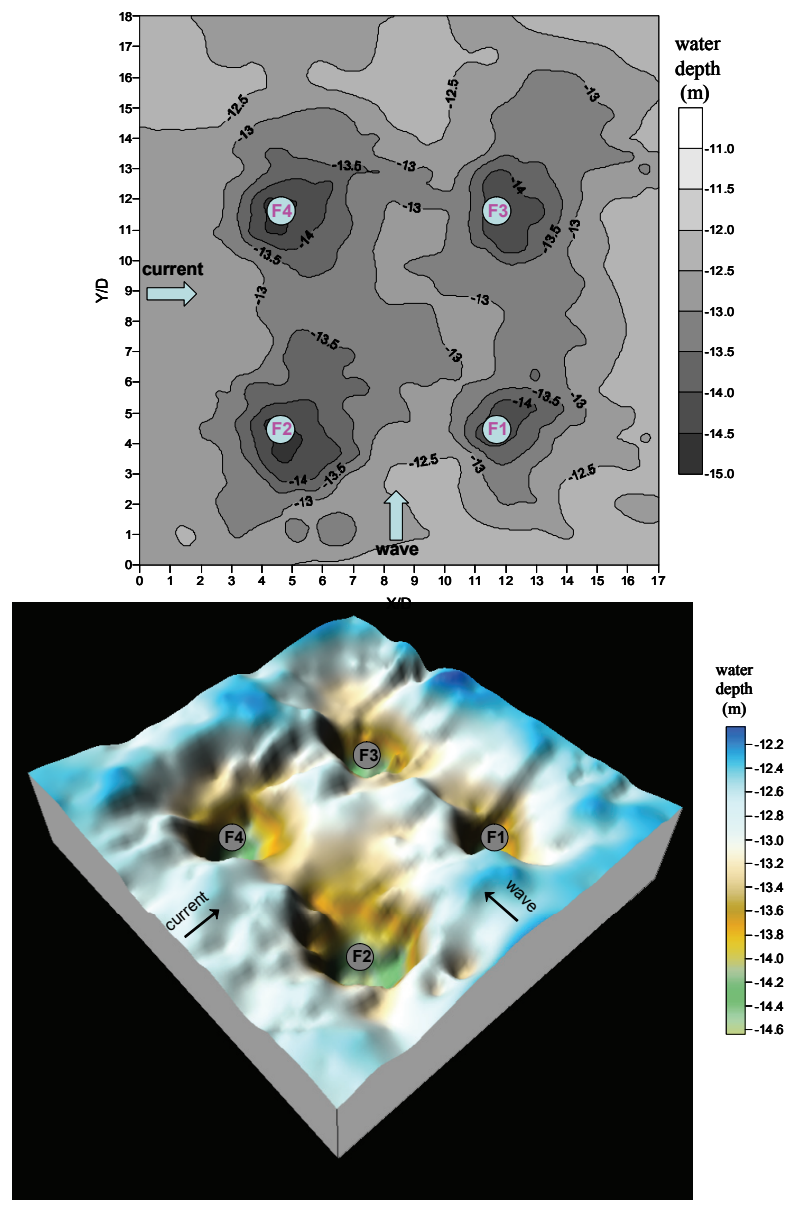

Figure 7. The 2D and 3D potential impact erosion area and scour around four legs of the jacket type foundation under the case 12TLLCM. 


Table 5. Maximum scour depth around the jacket type foundation (water depth 16m)
under different hydrodynamic conditions.
\begin{tabular}{|l|l|l|l|l|l|l|l|l|}
\hline test case & $F 1(m)$ & $F 2(m)$ & $F 3(m)$ & $F 4(m)$ & $F 1 / D$ & $F 2 / D$ & $F 3 / D$ & $F 4 / D$ \\
\hline $16 T L L M$ & 1.12 & 0.90 & 1.23 & 0.97 & 0.54 & 0.43 & 0.59 & 0.47 \\
\hline 16 TMM & 1.40 & 1.36 & 1.37 & 1.34 & 0.67 & 0.65 & 0.66 & 0.65 \\
\hline $16 S L L M$ & 0.76 & 0.68 & 0.69 & 0.74 & 0.37 & 0.32 & 0.33 & 0.36 \\
\hline $16 S L M$ & 0.72 & 0.69 & 0.67 & 0.66 & 0.35 & 0.33 & 0.32 & 0.32 \\
\hline $16 S M M$ & 0.68 & 0.58 & 0.60 & 0.66 & 0.33 & 0.28 & 0.09 & 0.32 \\
\hline 16 TLLCM & 1.68 & 2.37 & 1.65 & 2.42 & 0.81 & 1.14 & 0.79 & 1.17 \\
\hline 16 TMCM & 1.65 & 1.98 & 1.62 & 1.92 & 0.79 & 0.95 & 0.78 & 0.92 \\
\hline $16 S L L C M$ & 1.08 & 2.09 & 0.99 & 1.97 & 0.52 & 1.00 & 0.48 & 0.95 \\
\hline $16 S L C M$ & 0.99 & 1.96 & 1.01 & 2.01 & 0.48 & 0.94 & 0.48 & 0.97 \\
\hline $16 S M C M$ & 0.96 & 1.96 & 0.97 & 1.91 & 0.46 & 0.94 & 0.47 & 0.92 \\
\hline
\end{tabular}

\begin{tabular}{|c|c|c|c|c|c|c|}
\hline \multirow{2}{*}{ test case } & \multicolumn{6}{|c|}{ Impact area of the different scour depth from foundation leg } \\
\hline & $>0.2 \mathrm{~m}$ & $>0.5 \mathrm{~m}$ & $>1.0 \mathrm{~m}$ & $>1.5 \mathrm{~m}$ & $>2.0 \mathrm{~m}$ & $>2.5 \mathrm{~m}$ \\
\hline 16TLLM & $2 \sim 3 D$ & 1 1.5D & $0.5 \mathrm{D}$ & --- & --- & --- \\
\hline 16TMM & $\begin{array}{l}4 \sim 6 D \\
\end{array}$ & $1.5 \sim 2.5 \mathrm{D}$ & $0.5 \sim 1 \mathrm{D}$ & --- & --- & --- \\
\hline 16SLLM & $1 \sim 1.5 \mathrm{D}$ & --- & --- & -- & --- & --- \\
\hline 16SLM & $1 \sim 1.5 \mathrm{D}$ & --- & --- & --- & --- & --- \\
\hline $16 \mathrm{SMM}$ & $1 \sim 1.5 \mathrm{D}$ & --- & --- & --- & --- & --- \\
\hline 16TLLCM & --- & $1.5 \sim 2.5 \mathrm{D}$ & $1 \sim 2 \mathrm{D}$ & $\begin{array}{l}0.5 \sim \\
1.5 \mathrm{D}\end{array}$ & $0.5 \mathrm{D}$ & --- \\
\hline 16TMCM & --- & $1.5 \sim 2.5 \mathrm{D}$ & $1 \sim 2 \mathrm{D}$ & $0.5 \sim 1 \mathrm{D}$ & --- & --- \\
\hline 16SLLCM & --- & $1 \sim 2 D$ & $0.5 \sim 1.5 \mathrm{D}$ & $0.5 \sim 1 \mathrm{D}$ & $0.5 \mathrm{D}$ & --- \\
\hline 16SLCM & --- & $1 \sim 2.5 \mathrm{D}$ & $1 \sim 2 \mathrm{D}$ & $1 \sim 1.5 \mathrm{D}$ & --- & --- \\
\hline $16 \mathrm{SMCM}$ & --- & $1.5 \sim 2 D$ & $1 \sim 1.5 \mathrm{D}$ & $1 \sim 1.2 \mathrm{D}$ & --- & --- \\
\hline
\end{tabular}

\section{SCOUR PROTECTION FOR JACKET TYPE FOUNDATION OF OFFSHORE WIND TURBINE}

When the occurrence or uncertainties of a local scour hole around the foundation of wind turbine are not desired, preventive or remedial countermeasure can be applied. Almost all of today's knowledge about scour behavior and the strategy of scour protection is based on physical experiment carried out in flumes in codirectional waves and current, with two-dimensional waves (for example of Sumer and Fredsoe, 2002).Typically, the scour protection will be realized by using layers of natural, crushed rock, increasing in size when going up from the seabed. The lowest layer of rock, which is small enough to restrain the soil, can be replaced by a geotextile(den Boon J.H. et al.,2004).

Therefore based on the analysis from the former NSWB experimental results, the suitable scour protection for jacket type foundation of offshore wind turbine is proposed and shown in Fig.8. The proposed scour protection consists of :

(1) precast concrete block: $2 \mathrm{~m} \times 2 \mathrm{~m} \times 1 \mathrm{~m}$,

(2) armour stones: $0.5 \sim 1.0$ ton, with layer thickness of $1.4 \mathrm{~m}$,

(3) filter stones: $5 \sim 100 \mathrm{~kg}$, with layer thickness of $0.6 \mathrm{~m}$,

(4) geotextile (No.4).

The edge of the scour protection attains a slope of $1 \mathrm{~V}: 2 \mathrm{H}$. The experimental setup of scour protection is shown in Fig.9. The initial bed levels and sour protection block level are checked with bed profiles taken using a calibrated automatic bottom profiler. Pre-and post-test profiles are used to identify any settlement and stability in the precast concrete block and scour in the surrounding seabed. From Fig.10 and Fig.11, the results show that the protection block maintained the initial level and kept stable. But, there are scouring of the bed outside the protection by up to $1.2 \mathrm{~m}$, and inside the foundation by up to $1.8 \mathrm{~m}$ locally. However, a four-layer scour protection is tested and found to be effective in preventing scour around jacket type foundation of offshore wind turbine. 


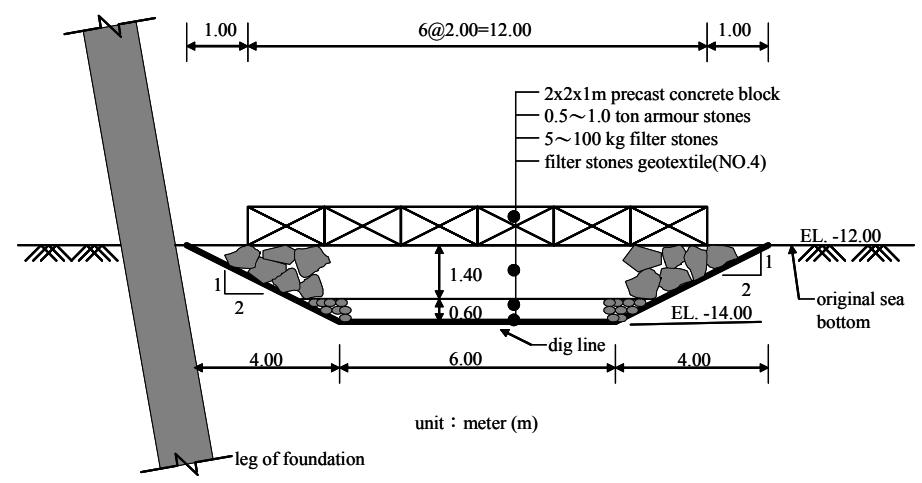

Figure 8. Sketch of the proposed scour protection.

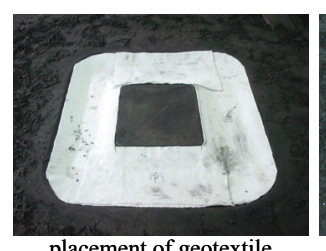

placement of geotextile

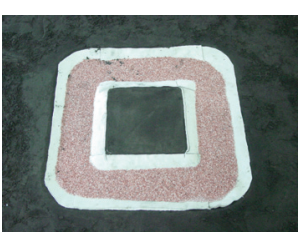

placement of filter stones

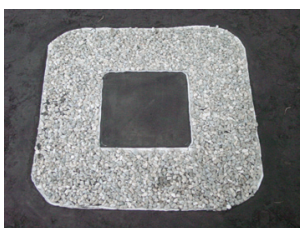

placement of armour stones
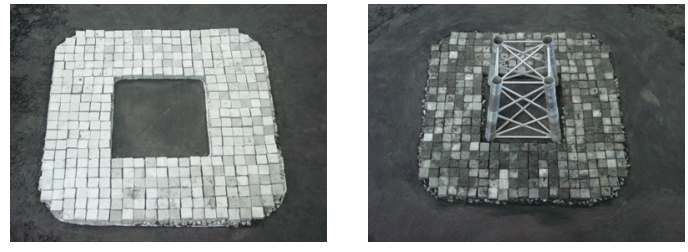

model of scour protection

Figure 9. The experimental setup of scour protection.
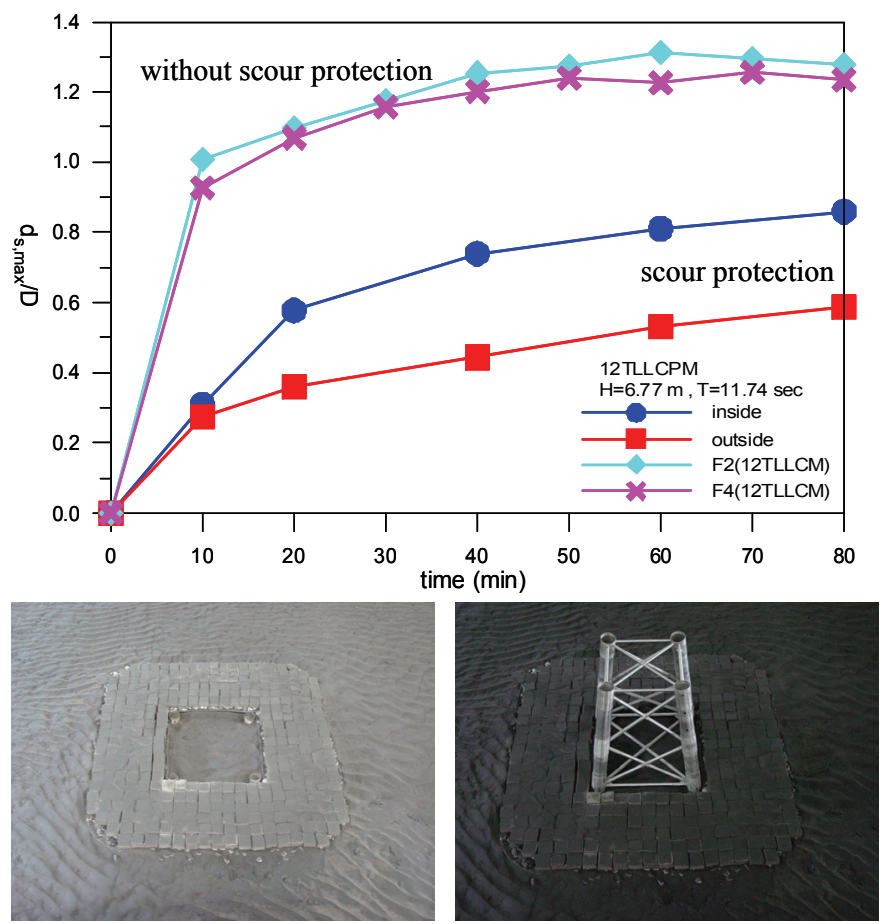

Figure 10. Comparison of maximum scour depth with the case 12TLLCM (without scour protection) and the case 12TLLCPM (with scour protection). 


\section{CONCLUSION}

The loading of typhoon wave with current on the jacket type offshore wind turbine foundation is investigated by the fixed bed experiment in this paper. The fixed bed experimental analysis is focused on the evaluation of the hydrodynamic force and on the prediction of the maximum breaking wave load on the jacket type offshore wind turbine foundation under shallow water condition. The results of fixed bed experiment indicate the maximum horizontal forces on the wind turbine foundation have a good agreement with those from the designed values and also validate the structure design of the engineering consulting company.

This paper also presents the results of a study into the scour around the jacket type offshore wind turbine foundation being considered for use in the mid-western coastal wind farm development of the TAIWAN. The scour and scour mitigation investigation is carried out in a wave-current basin to provide a deep understanding of flow-structure interaction. The ratio of maximum scour depth to leg diameter (D) of jacket type foundation and the potential impact scour area can be obtained from the results of this physical model tests. Meanwhile, a four-layer scour protection is tested and found to be effective in preventing scour around jacket type foundation of offshore wind turbine. Although it is common practice to apply scour protection at sites with a potential for local scour, the analysis of this study indicate that the function of protection is likely to provide a technically acceptable solution. Furthermore, the study of design solutions with and without scour protection will be investigated by the comparison with respect to technical feasibility, risks and costs in the near future.

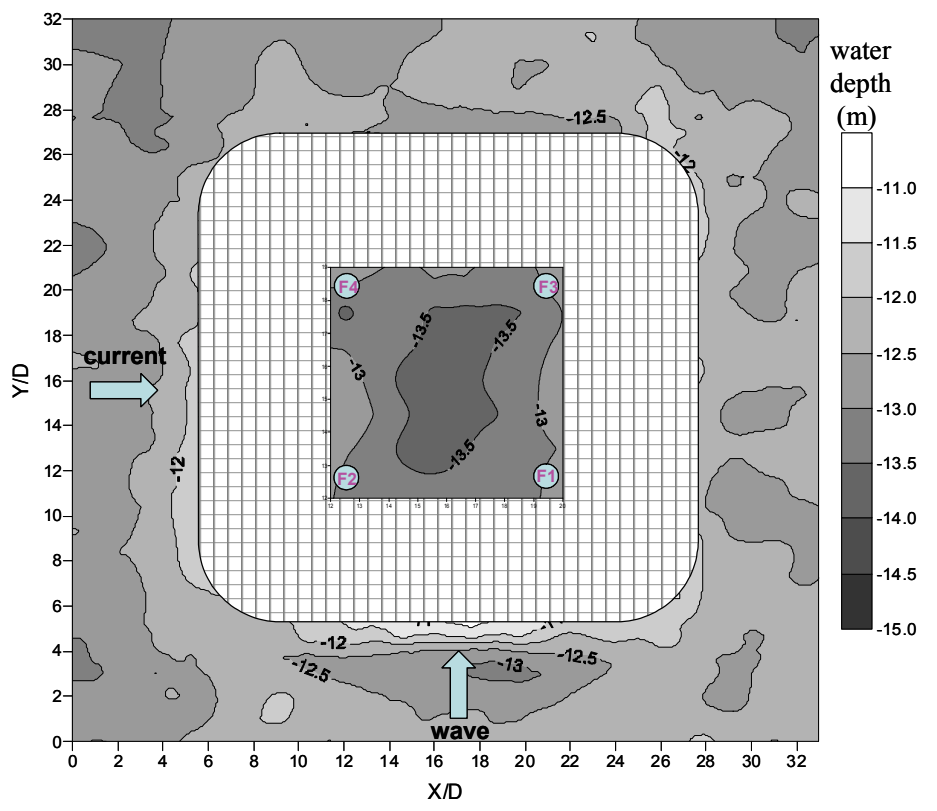

Figure 11. The potential impact erosion area around scour protection of the jacket type foundation under the case 12TLLCPM.

\section{ACKNOWLEDGMENTS}

The financial support from the Sinotech Engineering Consultants, LTD and the Taiwan Power Company (TPC) is gratefully acknowledged.

\section{REFERENCES}

De Bruyn, C. A. 1988. Scour near platform pier due to current and breaking waves,(in Dutch), Dept. of Coastal Eng., Delft Univ. Technology, Deft, The Netherlands.

den Boon, J.H., Sutherland, J., Whitehouse, R., Soulsby, R.,Stam, C.J.M., Verhoeven, K., Hogedal, M. and Hald, T. 2004. Scour Behaviour and Scour Protection for Monopile Foundations of Offshore Wind Turbines, In: Proceedings 2004 European Wind Energy Conference, London, UK. European Wind Energy Association[CD-ROM],pp. 14.

Schachner, Josef. 2004. Power connections for offshore wind farms, Delft University/ University of Leoben, Delft/Leoben, Januari.

Sumer, B. M., Fredsoe, J., Christiansen, N. 1992. Scour around vertical pile in waves, ASCE J. Waterw., Port, Coastal Ocean Eng. 118(1), 15-31.

Sumer, B. M. and Fredsoe, J. 2002. The Mechanics of Scour in the Marine Environment, World Scientific, Singapore. 